\title{
Management of Atmosphere Resources in Hydrometeorological Disaster Mitigation
}

\section{F. Heru Widodo, Tukiyatdan R. Djoko Goenawan}

Balai Besar Teknologi Modifikasi Cuaca, Badan Pengkajian dan Penerapan Teknologi Geostech PUSPIPTEK Serpong-Banten

heru.widodo@bppt.go.id

\section{Article History \\ accepted 31/08/2020}

approved 22/09/2020 published 28/10/2020

\begin{abstract}
Hydrometeorological disaster management in Indonesia such as floods, drought, tornadoes, etc., which occur almost every year in Indonesian territory, is carried out with structural efforts, however, it seems that the occurrence of disasters is still occurring even the intensity is increasing. To minimize the occurrence of hydrometeorological disasters, it is necessary to try a non-structural approach, namely the Weather Modification Technology (WMT). The application of WMT for hydrometeorological disaster mitigation can be used as an alternative solution in disaster risk reduction in Indonesia. The current WMT can be used to increase rainfall, to reduce rainfall, to mitigate floods and to reduce smoke due to forest and land fires. The application of WMT for additional rainfall is able to increase rainfall by about $30 \%$, while to reduce rainfall, it can reduce rainfall by about 30-35\%. This technology can be used as an integral part in the management of water resources in Indonesia.
\end{abstract}

Keywords: Weather Modification Technology, Hydrometeorological disaster

\begin{abstract}
Abstrak
Penanggulangan bencana hidrometeorologi di Indonesia seperti banjir, kekeringan, puting beliung dll yang hampir setiap tahun terjadi di wilayah Indonesia dilakukan dengan upaya secara structural, namun demikian sepertinya kejadian bencana masih tetap aja terjadi bahkan intensitasnya semakin meningkat. Untuk meminimalisir terjadinya bencana hidrometeorologi tersebut perlu dicoba usaha pendekatan non structural yaitu dengan Teknologi Modifikasi Cuaca (TMC). Penerapan TMC untuk mitigasi bencana hidrometeorologi dapat dijadikan alternative solusi dalam pengurangan resiko bencana di Indonesia. TMC saat ini, dapat digunakan untuk menambah curah, untuk mengurangi curah hujan, penanggulangan banjir serta untuk penipisan asap akibat kebakaran hutan dan lahan. Penerapan TMC untuk penambahan curah hujan mampu menambah curah hujan sekitar $30 \%$ sedang untuk mengurangi curah hujan, mampu mengurangi curah hujan sekitar $30-35 \%$. Teknologi ini dapat dijadikan bagian integral dalam pengelolaan sumber daya air di Indonesia.
\end{abstract}

Kata Kunci: Teknologi Modifikasi Cuaca, bencana Hidrometeorologi,

Social, Humanities, and Education Studies (SHEs): Conference Series https://jurnal.uns.ac.id/shes

p-ISSN 2620-9284

e-ISSN 2620-9292 


\section{PENDAHULUAN}

Terjadinya pemanasan global telah berdampak terhadap perubahan iklim dan cuaca, hal ini terlihat dari eskalasi bencana alam khususnya bencana hidrometeorologi yang mempunyai kecenderungan meningkat. Bencana banjir, longsor, kekeringan, putting beliung, kebakaran hutan dan lahan intensitas kejadiannya semakin meningkat. Kejadian bencana hidrometeorologi di Indonesia mendominasi lebih dari 90 persen bencana yang terjadi pada tahun 2019 lalu. Catatan yang dikeluarkan oleh Badan Nasional Penanggulangan Bencana (BNPB), sepanjang tahun 2019 telah terjadi 3.758 kejadian bencana baik yang disebabkan oleh bencana hidrometeorologi maupun bencana alam lainnya, dengan perincian: 1.363 puting beliung, 746 Karhutla, 764 banjir, 123 kekeringan, 708 Tanah longsor, 29 gempa bumi, 7 erupsi gunung api, 18 pasang dan abrasi (Kompas.com, 28 Desember 2019).

Selain disebabkan oleh adanya perubahan pola iklim dan cuaca, bencana alam di Indonesia khususnya bencana banjir dan kekeringan juga disebabkan rusaknya kondisi lahan, sehingga pada saat musim hujan langsung terjadi banjir dan pada saat musim kemarau terjadi kekeringan dan merembet ke bencana kebakaran hutan dan lahan. Lahan tidak mampu lagi menyimpan air hujan pada saat musim penghujan, air hujan sebagian besar menjadi aliran permukaan (run off) sehingga pada saat musim kemarau langsung terjadi kekeringan. Kementerian Lingkungan Hidup dan Kehutanan (KLHK) melansir sebanyak 108 Daerah Alisan Sungai (DAS) di Indonesia berada dalam keadaan kritis dan merupakan prioritas untuk direvitalisasi (Republika.co.id, 26 September 2016). Kondisi ini yang akan menjadi pemicu bencana banjir dan kekeringan di Indonesia yang eskalasinya semakin tahun semakin meningkat. Untuk mengatasi permasalahan ini berbagai program telah dan akan ditempuh oleh pemerintah dengan berbagai kebijakan pembangunan seperti perbaikan lahan kritis, pembangunan waduk, pembangunan dan perbaikan gorong-gorong, rehabilitasi saluran irigasi dll. Kebijakan dalam mengatasi bencana ini banyak lebih bersifat pendekatan struktural, sedangkan kebijakan pembangunan non struktural masih sangat kurang sehingga sering kejadian bencana masih terjadi. Untuk meminimalisir terjadinya bencana hidrometeorologi tersebut perlu dicoba usaha pendekatan non struktural diantaranya dengan pengelolaan sumberdaya di atmosfer.

Badan Pengkajian dan Penerapan Teknologi lewat Balai Besar Teknologi Modifikasi Cuaca memberikan solusi alternative dalam mengurangi bencana banjir dan kekeringan serta kebakaran hutan dan lahan dengan pendekatan pengelolaan sumberdaya atmosfer menggunakan Teknologi Modifikasi Cuaca (TMC). Saat ini penerapan TMC selain digunakan untuk penambahan curah hujan dalam pengisian air waduk, juga digunakan untuk pengurangan curah hujan dalam mitigasi banjir serta penanggulangan bencana asap akibat kebakaran hutan dan lahan (Widodo, FH dkk, 2015).

Metode yang digunakan dalam penerapan TMC adalah Metode Jumping proses, metode kompetisi dan metode overseed seeding. Penerapan TMC di Indonesia pada awalnya untuk pengisian air waduk, terus berkembang untuk penipisan asap akibat kebakaran hutan dan lahan dan dikembangkan kembali untuk pengurangan curah hujan dalam penanggulangan banjir perkotaan serta pengurangan curah hujan di daerah pertambangan. Hasil evaluasi penerapan TMC untuk penambahan curah hujan bisa menambah curah hujan sekitar $20-30 \%$ dari curah hujan alaminya, sedangkan penerapan TMC untuk pengurangan curah hujan bisa mengurangi curah hujan antara 30-35\% dari curah hujan. Manfaat TMC di Indonesia semakin dirasakan masyarakat terlihat dari semakin meningkatnya permintaan TMC 
dari tahun ke tahun, dari mulai tahun 1979 sampai Desember 2019 dan tujuannya semakin beragam (lihat Gambar 1).

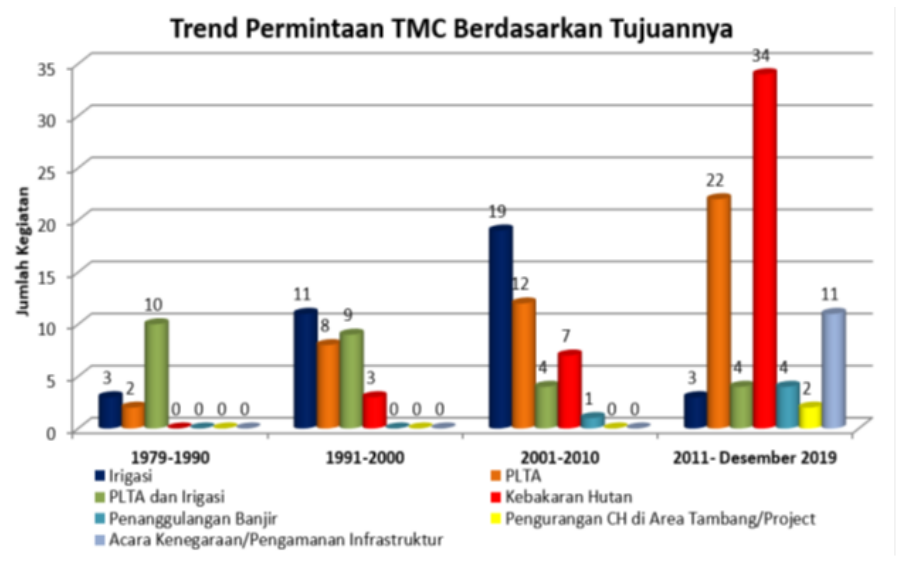

Gambar 1. Trend permintaan TMC Alaminya

Kalau dilihat dari Gambar 1 pada 10 tahun pertama antara 1979-1990, jumlah penerapan TMC baru sekitar 13 kali kegiatan dan tujuannya hanya untuk pengisian waduk dan irigasi, namun dari tahun ke tahun permintaan TMC semakin meningkat tajam dan tujuan penggunaannya juga semakin beragam. Pada sembilan tahun terakhir dari tahun 2011-2019, permintaan TMC mencapai 80 kegiatan dengan tujuan kegiatan cukup beragam dari pengisian waduk, kebakaran hutan sampai untuk mitigasi banjir. Sampai dengan tahun 2019, Teknologi Modifikasi Cuaca telah diterapkan sebanyak 164 kali di berbagai daerah di Indonesia. Tujuan penulisan ini menguraikan penerapan TMC di Indonesia dalam pengelolaan sumberdaya atmosfer untuk mitigasi bencana hidrometeorologi

\section{METODE}

Teknologi Modifikasi Cuaca adalah usaha campur tangan manusia dalam pengendalian sumberdaya air di atmosfer untuk menambah curah hujan dan mengurangi intensitas curah hujan pada daerah tertentu untuk meminimalkan bencana alam yang disebabkan oleh iklim dan cuaca dengan memanfaatkan parameter cuaca. Pada saat ini dalam penerapan TMC untuk Mitigasi Bencana kekeringan, mitigasi bencana karhutla dan mitigasi bencana banjir menggunakan beberapa metode yaitu:

1. Metode Jumping proses (metode lompatan)

Metode dilakukan dengan cara memasukan bahan semai higroskopik ke dalam awan dengan diameter butir yang lebih besar dengan besar butir inti kondensasi alam, agar proses penumbukan dan penggabungan yang ada di dalam awan akan semakin efisien dan cepat menjadi hujan (lihat Gambar 2).

2. Metode Kompetisi

Metode ini banyak digunakan untuk mengganggu pertumbuhan awan di daerah yang rawan banjir agar tidak turun hujan, dengan cara memasukan bahan semai yang mempunyai diameter halus seperti inti kondensasi yang ada di alam dalam jumlah yang banyak sehingga pertumbuhan awan terganggu (lihat Gambar 3). 


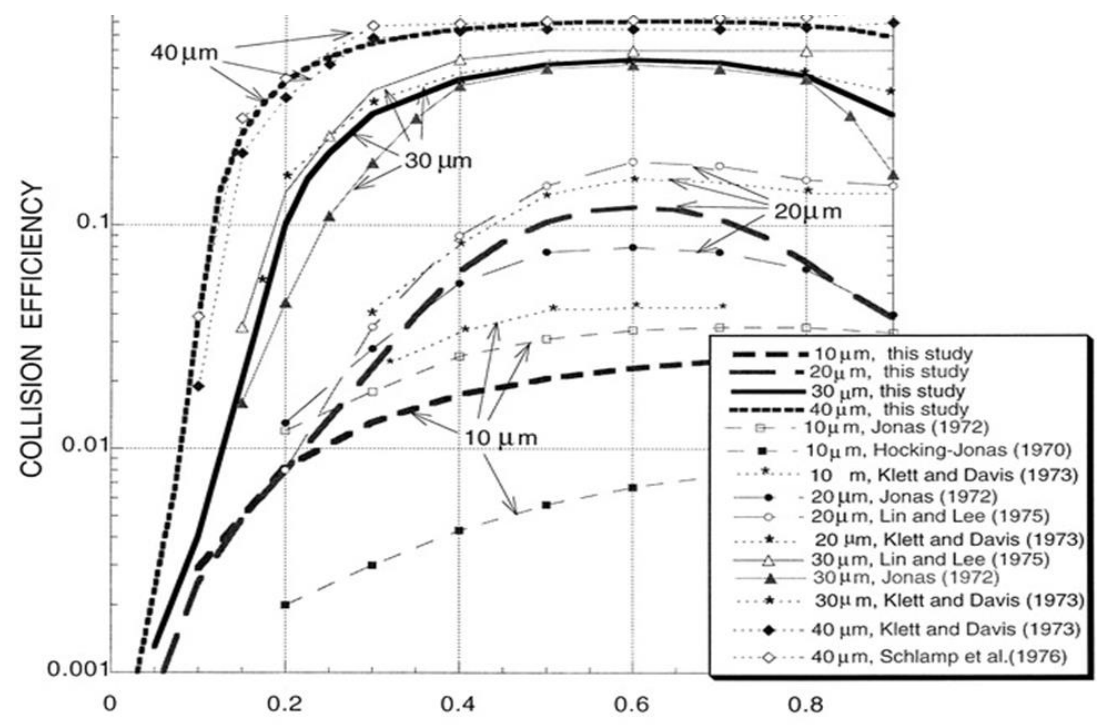

Gambar 2. Efisiensi Tumbukan Dan Penggabungan

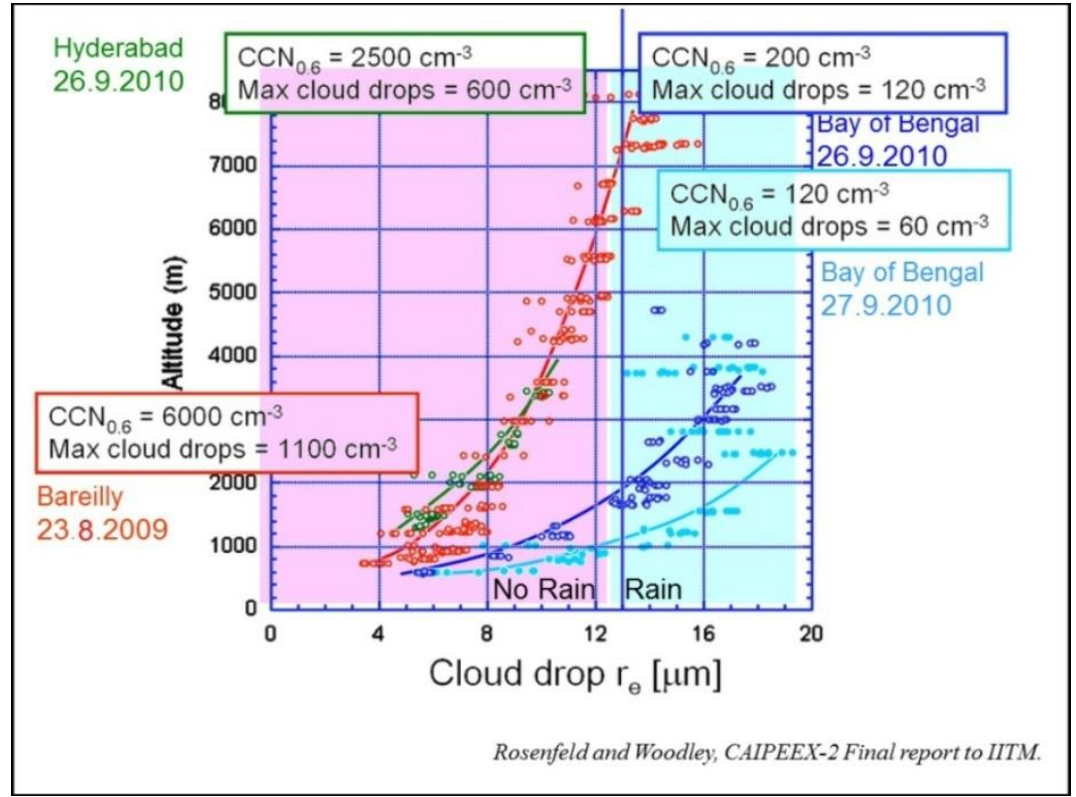

\section{Gambar 3. Hubungan Antara Jumlah Inti Kondensasi Dengan Besarnya Tetesan Butir Awan Sampai Terjadi Hujan}

Pada grafik terlihat, dengan kita memasukkan jumlah bahan semai yang cukup banyak dengan besar butir yang mirip dengan alam ke dalam awan, maka pertumbuhan awan terganggu dan tidak menjadi hujan/buyar, atau hujan setelah mencapai ketinggian tertentu.

3. Metode Overseeded

Metode ini digunakan untuk membuyarkan awan dengan cara memasukan bahan semai secara berlebihan ke dalam awan sehingga pertumbuhan awan menjadi terganggu dan tidak menjadi hujan atau buyar. Tujuan penyemaian awan hanya untuk mentriger proses yang terjadi di dalam awan sehingga proses tumbukan dan 
penggabungan berjalan lebih cepat, sehingga bahan semai yang dibutuhkan tidak perlu terlalu besar jumlahnya.

Data yang digunakan dalam penulisan makalah ini menggunakan data kegiatan penerapan TMC di Indonesia dari tahun 1979 sampai tahun 2019.

\section{HASIL DAN PEMBAHASAN}

Penerapan TMC di Indonesia pada awalnya di gunakan untuk pertanian dan pengisian air waduk. Pada awalnya dilakukan percobaan di DAS Citarum Jawa Barat sekitar tahun 1979 pada era Presiden Soeharto yang sebelumnya memerintahkan Prof. BJ Habiebie untuk belajar teknologi ini di Thailand yang telah lebih dulu menerapkan teknologi ini untuk menunjang kebutuhan air pertaniannya sehingga Thailand menjadi negara di asia yang cukup maju bidang pertaniannya. Hasil pengkajian teknologi TMC ini untuk menunjang pertanian di wilayah DAS Citarum dinilai sangat baik dan TMC bisa diterapkan di Indonesia karena secara iklim dan cuaca wilayah Indonesia masih mirip dengan wilayah Thailand, sehingga pada tahun 1985 didirikan Unit Pelaksana Teknis Hujan Buatan untuk melaksanakan pelayanan TMC di Indonesia dalam pengelolaan sumberdaya air khususnya untuk pengisian air waduk dan pertanian di Indonesia.

Mulai tahun 1985 penerapan TMC di Indonesia berkembang cukup pesat khususnya untuk pengisian waduk-waduk di Indonesia seperti Waduk Ir. Juanda, Waduk Saguling, Waduk Cirata, Waduk Sutami, Waduk Ir. M. Noor dan waduk-waduk lainnya baik di Jawa maupun luar Jawa. Pengkajian TMC untuk penerapan di sector lainnya tetap dilakukan, sehingga pada sekitar tahun 2006, TMC dipercaya untuk membantu penanggulangan bencana asap dan karhutla di Sumatera dan Kalimantan, baru pada tahun 2011, TMC dipercaya kembali untuk membantu pengamanan penyelenggaraan Sea Games di Palembang sejak penyiapan venue, pembukaan, penyelenggaraan sampai penutupan SeaGames. Mulai saat itu, permintaan TMC di 3 sektor kegiatan yaitu untuk pertanian, penipisan asap karhutla dan pengurangan curah hujan meningkat tajam termasuk untuk pengurangan curah hujan di daerah areal pertambangan batu bara serta pengamanan even-even kenegaraan agar tidak terganggu karena hujan. Kegiatan penerapan TMC untuk mitigasi hidrometeorologi khususnya bencana kekeringan, banjir serta kebakaran hutan di Indonesia akan dijelaskan secara rinci sebagai berikut:

A. TMC untuk mitigasi bencana Kekeringan

Sektor pertanian ini menjadi tujuan awal dilakukannya TMC di Indonesia, beberapa waduk di Indonesia sudah menjadi langganan tetap dilakukannya kegiatan penambahan curah hujan untuk pengisian waduk guna menunjang kegiatan pertanian dimasa kemarau sekaligus dipakai untuk menggerakan turbin PLTA. Secara regulasi, kegiatan TMC untuk menambah curah hujan tertuang dalam UU Nomor 17 Tahun 2019 tentang Sumberdaya Air dalam Pasal 29 ayat 2, tentang "Pendayagunaan Sumber Daya Air" dilakukan melalui kegiatan pengembangan sumber daya air. Adapun Peningkatan kemanfaatan fungsi Sumber Daya Air antara lain melalui Modifikasi Cuaca"

Teknologi Modifikasi Cuaca merupakan intervensi manusia pada proses pembentukan hujan di dalam awan. Hasil intervensi ini, proses di dalam awan akan menjadi lebih efisien daripada proses berjalan secara alami, yaitu proses tumbukan dan penggabungan antara tetes awan dengan partikel bahan semai yang telah berubah dari padatan menjadi cairan. Intervensi dilakukan dengan menginjeksikan bahan yang disebut bahan semai (seeding agent) ke dalam awan (lihat Gambar 4) 


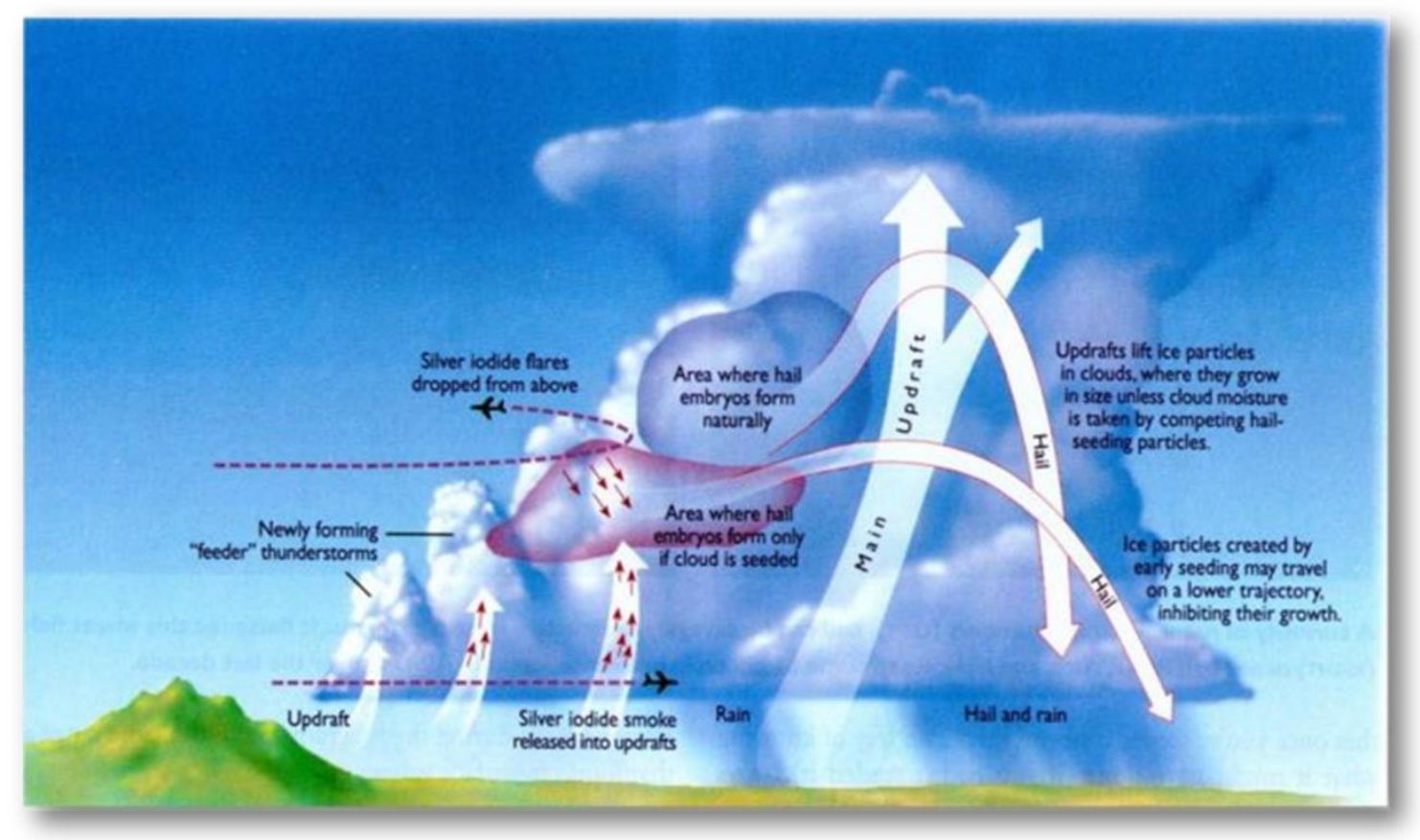

Gambar 4. Proses Penginjeksian Bahan Semai Ke Dalam Awan

Bahan semai yang di injeksikan ke dalam awan berupa bahan powder yang sangat halus atau behan semai yang sudah dipadatkan menjadi "flare" dan di bakar yang menghasilkan bahan semai berupa asap (lihat Gambar 5).

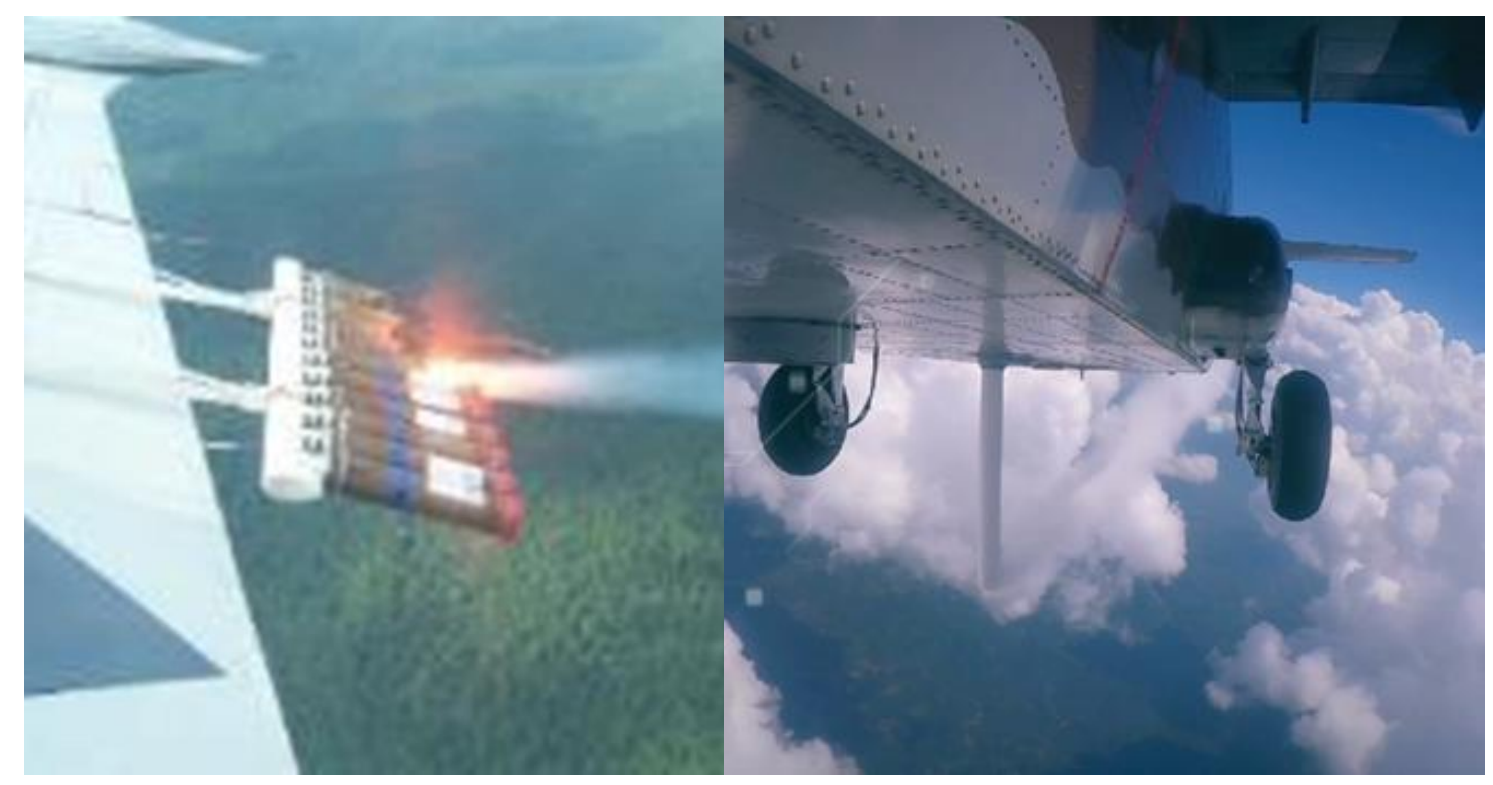

Gambar 5. Bahan Penyemai Awan Berupa Powder Dan Flare

Hasil evaluasi kegiatan TMC untuk penambahan curah hujan, mampu menambah curah hujan rata-rata sekitar $30 \%$ dari curah hujan alaminya. Pelaksanaan penerapan TMC untuk penambahan curah hujan di waduk dan areal pertanian dapat dilihat pada Lampiran 1. 


\section{B. TMC untuk mitigasi bencana Karhutla}

Secara regulasi, peranan TMC untuk mitigasi bencana kebakaran hutan dan lahan telah tertuang dalam Instruksi Presiden Republik Indonesia Nomor 3 Tahun 2020 tentang Penanggulangan Kebakaran Hutan dan Lahan, dimana Presiden RI memberikan instruksi kepada Ka BPPT untuk melakukan operasi modifikasi cuaca dan pengembangan teknologi pembukaan lahan tanpa bakar untuk mendukung upaya penanggulangan Karhutla.

Ketika berlangsung kebakaran hutan, atmosfer sangat sedikit mengandung uap air ( $\mathrm{RH}$ rendah). Selain itu, terbakarnya biomasa menyebabkan populasi atau jumlah inti-kondensasi di atmosfer meningkat sangat besar. Kondisi ini menimbulkan kompetisi (persaingan) memperebutkan uap air yang saat itu jumlahnya tidak besar. Keadaan ini menyebabkan sangat sulit terbentuk awan. Kalaupun ada awan, awan ini tidak dapat berkembang besar sehingga sulit untuk terjadinya hujan. Pada saat terjadinya kebakaran hutan dan lahan biasanya kondisi cuacanya menjadi stabil dan radiasi matahari ke bumi berkurang. Karena kondisi cuacanya stabil maka mengakibatkan asap akibat kebakaran hutan dan lahan sulit terbuang ke angkasa sehingga semakin lama mengakibatkan jarak pandang menjadi terganggu dan Indeks Standard Pencemaran Udara (ISPU) semakin meningkat sehingga mengganggu pernafasan (Sandhyavitri A, 2018). Pada saat kondisi asap sudah pekat, kondisi cuaca yang stabil, kelembaban udara yang kering maka turunnya curah hujan menjadi hal yang sangat penting untuk membersihkan udara karena asap, supaya kondisi radiasi matahari semakin membaik, proses konveksi berjalan kembali dan cuacanya menjadi labil sehingga proses pembentukan awan berjalan kembali secara alami (lihat Gambar 6)

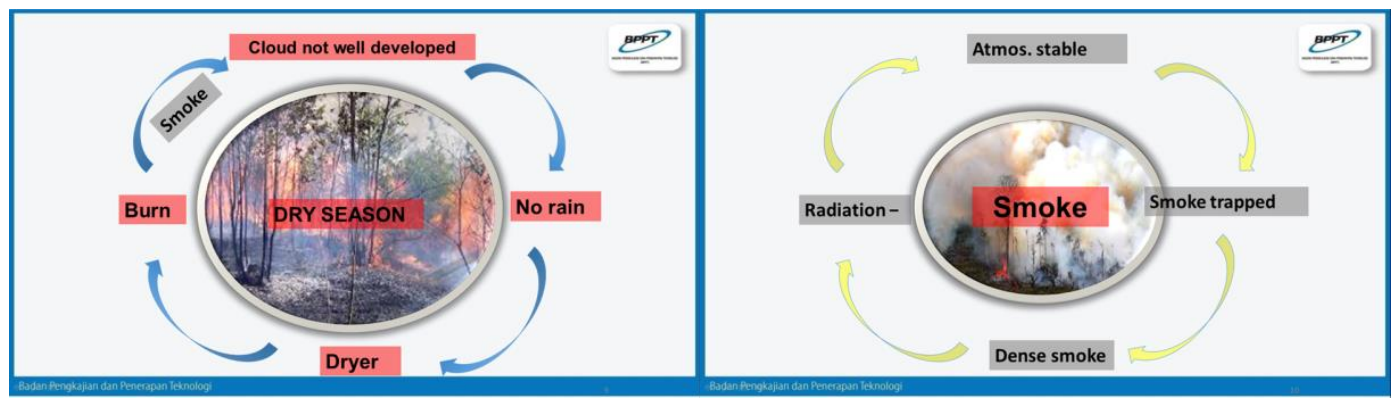

Gambar 6. Kondisi Cuaca Stabil Saat Terjadinya Karhutla, Awan Sulit Terbentuk.

Inilah peran penting TMC dalam memodifikaci cuaca bagaimana dapat mengoptimalkan kondisi awan yang ada untuk dipercepat menjadi hujan. Hanya hujan yang mampu membilas asap yang ada dan mengembalikan kondisi cuaca menjadi labil atau normal kembali. Fungsi utama TMC tidak hanya dilihat hasilnya dari jumlah air yang jatuh karena mendapat perlakukan penyemaian, namun justru dengan adanya hujan maka dapat mengembalikan kondisi cuaca menjadi normal kembali dan proses konveksi alami terjadi kembali dan pertumbuhan awan semakin baik untuk diberi perlakukan menjadi hujan. Bila di atas suatu daerah kebakaran atmosfernya berubah menjadi mendukung (favourable) yaitu dengan masuknya masa udara lembab dan terjadinya konveksi, maka awan-awan di daerah ini akan tumbuh dan semakin berkembang. Pada kondisi seperti inilah peran TMC sangat efektif, yaitu mempercepat proses terjadinya hujan untuk meningkatkan intensitas hujan, meluaskan daerah hujan dan memperpanjang durasi (lama) hujan sehingga titik api menjadi padam dan asap hilang sehingga udara menjadi normal kembali. Penerapan TMC untuk karhutla di Indonesia dapat dilihat pada Lampiran 1. 
C. TMC untuk mitigasi bencana Banjir

Penerapan TMC untuk mitigasi bencana banjir, memerlukan usaha (effort) yang lebih besar dibanding untuk mitigasi kekeringan dan karhutla, hal ini dikarenakan banyaknya awan hujan yang harus dikendalikan agar tidak jatuh hujan di daerah rawan banjir (Seto TH, 2013). Biasanya 3 metode pelaksanaan TMC dilakukan bersama-sama yaitu metode jumping proses, metode kompetisi dan metode overseeded, sehingga wahana yang digunakan juga sangat beragam yaitu pesawat terbang lebih dari 1 buah dan ground partical generator yang jumlahnya bisa mencapai lebih dari 10 buah. Pelaksanaan TMC untuk pengurangan curah hujan pada prinsipnya kita mengelola potensi perawanan yang ada di wilayah rawan banjir dijatuhkan di daerah yang masih aman, bisa dijatuhkan di waduk, di daratan yang masih aman menampung curah hujan, dan jika terpaksa baru dijatuhkan di lautan. Hujan dengan intensitas ringan dan sedang jika masih aman tidak menyebabkan banjir akan tetap dijatuhkan di daerah target. Dalam konteks mitigasi bencana banjir; Ka. BPPT mendapat instruksi melalui Inpres No.4 tahun 2012, tentang Penanggulangan Bencana Banjir dan Tanah Longsor. Ilustrasi prosedur operasi penerapan TMC untuk mitigasi banjir bisa dilihat pada Gambar 7, contoh untuk wilayah Jabodetabek.

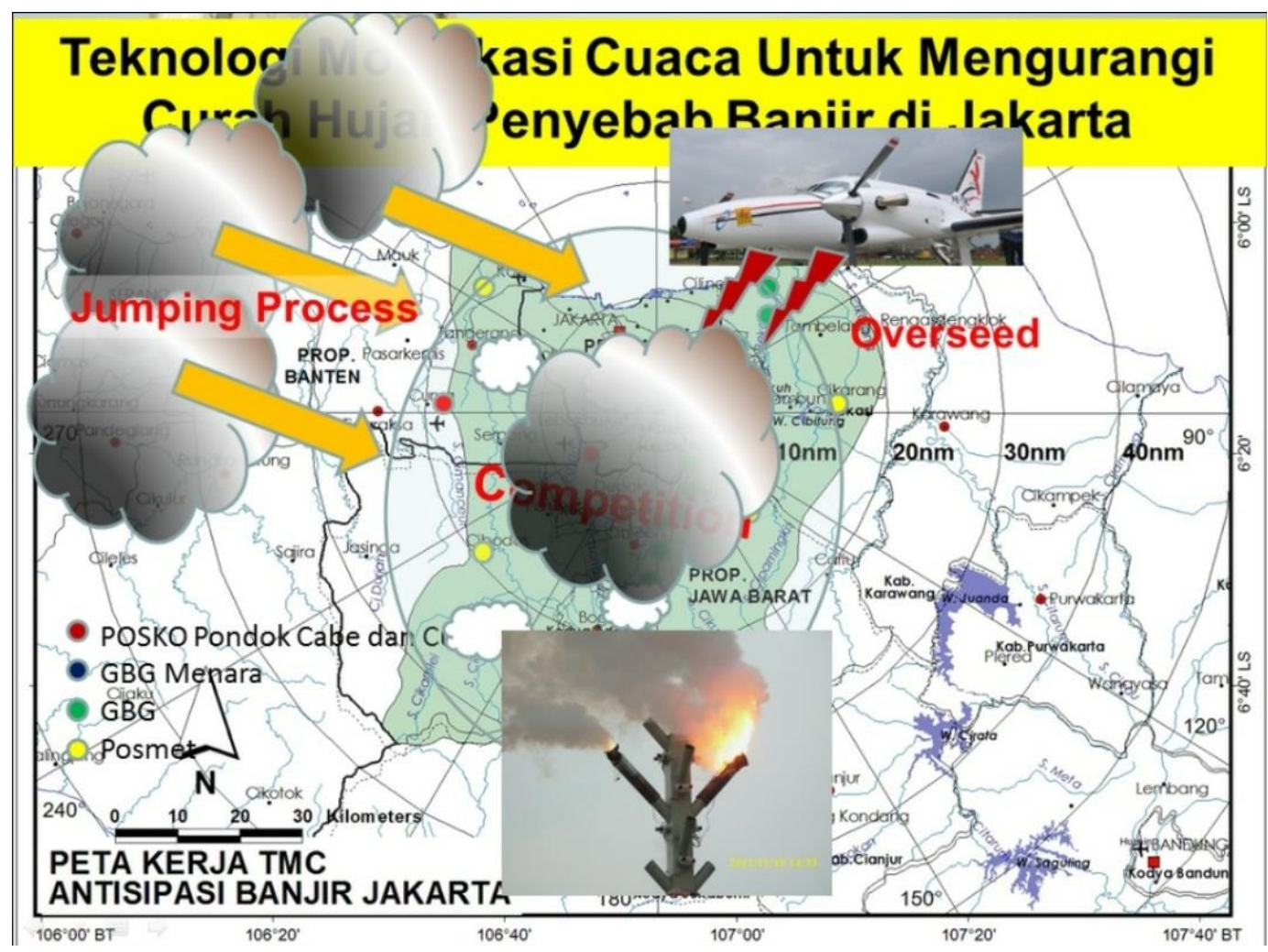

Gambar 7. Ilustrasi Prosedur Operasi Penerapan TMC Untuk Mitigasi Banjir.

Hasil evaluasi kegiatan TMC untuk pengurangan curah hujan, mampu mengurangi curah hujan rata-rata sekitar 30-35\% dari curah hujan alaminya. (Harsoyo, Budi (2015). Pelaksanaan penerapan TMC untuk pengurangan curah hujan dapat dilihat pada Lampiran 1.

Penerapan Modifikasi cuaca di Indonesia telah berjalan selama 35 tahun, secara regulasi penerapan TMC sudah memenuhi aturan baik penerapan TMC untuk penambahan curah hujan, pengurangan curah hujan maupun untuk penanggulangan 
bencana kebakaran hutan dan lahan. Unuk itu perlu adanya ekosistem TMC agar kemajuan teknologi ini bisa semakin di akselerasi dan semakin dimanfaatkan dalam pengelolaan sumberdaya air di Indonesia.

\section{SIMPULAN}

Dari uraian di atas ada beberapa simpulan pokok dalam tulisan ini yaitu:

1. Teknologi Modifikasi Cuaca dapat dijadikan teknologi alternatif dalam mitigasi bencana Hidrometeorologi yaitu kekeringan, karhutla dan banjir dengan cara mengelola sumberdaya atmosfer khususnya awan yang ada di suatu wilayah.

2. Metode yang digunakan untuk pelaksanaan TMC adalah metode jumping proses, kompetisi dan overseeded.

3. Perlu adanya ekosistem TMC agar kemajuan teknologi ini bisa semakin di akselerasi dan semakin dimanfaatkan dalam pengelolaan sumberdaya air di Indonesia.

\section{DAFTAR PUSTAKA}

Harsoyo, Budi dkk, 2015.Efektifitas Teknologi Modifikasi Cuaca untuk Mitigasi Banjir. Arti penting Pengurangan Curah Hujan 30\% bagi Banjir Jakarta. Cetakan ke dua. BPPT Press: Jakarta.

Sandhyavitri A, Perdana MA, Sutikno S, Widodo FH (2018) The roles of weather modification technology in mitigation of the peat fires during a period of dry season in Bengkalis, Indonesia. In: TALENTA-CEST, IOP Conf. Series: Materials Science and Engineering. IOP Publishing, pp 0-9

Seto TH, Tikno S, Sutrisno, Widodo H, 2013. Pemanfaatan Teknologi Modifikasi Cuaca Untuk Redistribusi Curah Hujan dalam Rangka Tanggap Darurat Banjir di Provinsi DKI Jakarta dan Sekitarnya. J Sains Teknol Modif Cuaca 14:1-11

Putri, Melisa Riska, 2016. 108 Daerah Aliran Sungai di Indonesia kritis. Republika Online. Diakses dari http://republika.co.id, 26 September 2016

Tamtomo, Akbar Bhayu, 2019. Infografik: Kaleidoskop 2019, Bencana sepanjang tahun ini Kompas Online. Diakses dari http://www.kompas.com, 28 Desember 2019.

Widodo, FH, dkk, 2015. Peranan Teknologi Modifikasi Cuaca di Indonesia. Cetakan ke dua. BPPT Press, Jakarta. 